\title{
DIÁLOGO ENTRE A HISTÓRIA E A GEOGRAFIA SOBRE QUESTÕES AMBIENTAIS
}

\author{
DIALOG BETWEEN HISTORY AND GEOGRAPHY REGARDING ENVIRONMENTAL ISSUES
}

\section{RESUMO}

O tema central deste ensaio é apresentar uma análise da possível e necessária articulação interdisciplinar entre a História e a Geografia na abordagem de questões ambientais. O objetivo é demonstrar a aproximação dessas disciplinas através do uso comum de teorias/metodologias como a dialética, a teoria geral dos sistemas (TGS), o geossistema (GTP) e a história ambiental. A visão holística e integrada do ambiente e o uso de conceitos como território e paisagem, cada vez mais fazem parte de pesquisas que tratam das complexas relações entre a sociedade e a natureza, sobretudo após a crise ambiental contemporânea dos anos de 1970. Apontar caminhos teóricos que valorizem igualmente o espaço e o tempo na abordagem da temática ambiental é a solução indicada. Os procedimentos metodológicos utilizados foram as análises/interpretações da bibliografia e a contraposição das ideias dos principais autores envolvidos nesse debate. O trabalho concluiu pela viabilidade do uso comum do aparato teórico e metodológico de forma integrada pela História e Geografia no aprofundamento de pesquisas que discutam e apresentem diagnósticos, prognósticos e soluções para os principais problemas ambientais vividos pela humanidade, no passado e nos tempos atuais.

Palavras-chave: Sociedade e Natureza. Geossistema. História Ambiental.

\section{ABSTRACT}

The central theme of this essay is to present an analysis of the possible and necessary interdisciplinary articulation between History and Geography in the approach of environmental issues. The aim is to demonstrate the approximation of these subjects through the common use of theories / methodologies such as dialectics, the general theory of the systems (TGS), geosystem (GTP) and environmental history. The holistic and integrated view of the environment and the use of concepts such as territory and landscape, are increasingly being part of research that deals with the complex relations between society and nature, especially after the contemporary environmental crisis of the 1970s. Pointing theoretical paths that can equally value space and time in approaching the environmental issue is the indicated solution. The methodological procedures used were the bibliographical analysis/interpretations and the contrast of the ideas of the main authors involved in this debate. The paper concludes the feasibility of the common use of the theoretical and methodological apparatus integrated by History and Geography in the deepening of researches that discuss and present diagnoses, prognoses and solutions to the main environmental problems experienced by humanity in the past and in the present times.

Keywords: Society and Nature. Geosystems. Environmental History.

\author{
Dalton Melo Macambira ${ }^{a}$ \\ Iracilde Maria de Moura Fé \\ Lima ${ }^{\text {a }}$ \\ Daria do Socorro Lira \\ Monteiro "In Memorian" a \\ a Universidade Federal do Piauí (UFPI), \\ Teresina, $\mathrm{PI}$, Brasil
}

DOI: $10.12957 /$ geouerj.2020.40689

Correpondência: daltonmacambira@msn.com

Recebido em: 11 mar. 2019

Aceito em: 7 jan.2020 


\section{INTRODUÇÃO}

O objetivo deste ensaio é demonstrar como a História e a Geografia, em conjunto, podem contribuir para o estudo das relações da sociedade com a natureza, convergindo para ampliara compreensão dessas relações, ao utilizar a Teoria Geral dos Sistemas (TGS), por intermédio das metodologias do Geossistema e da História Ambiental.

Nessa perspectiva, de acordo com Vicente e Perez Filho (2003), o biólogo austríaco Ludwig von Bertalanffy (1901-1972) desenvolveu a TGS com publicações pioneiras nas décadas de 1950 e 1960, rompendo com o primado cartesiano e metafísico que partia do pressuposto que somente estudando isoladamente os fenômenos os mesmos poderiam ser compreendidos. Ressalta que a nova teoria se assentava em que somente era possível compreender determinado fenômeno partindo de um a visão sistêmica, holística, pois o sistema não é uma mera soma das partes, mas um todo articulado.

Destarte, embora se saiba que o sistemismo tem como perspectiva a harmonia, enquanto a dialética pressupõe o conflito permanente, contrária, portanto, a estabilidade sistêmica (ARECO, 1989), pode-se afirmar que, em certa medida, a TGS recuperou a dialética de Hegel e Marx do século XIX (BERTALANFFY, 2015), haja vista que o método dialético também considera que os fenômenos, partes de um determinado sistema, não podem ser compreendidos de forma isolada, pois mantem entre si uma relação de interdependência e influência mútua. Dessa forma, o sistema articula um conjunto de partes ou coisas que formam um todo unitário e complexo (ENGELS, 1978).

Baseada na TGS, conforme Oliveira (2012) foi elaborada nos anos de 1960 a teoria e a metodologia do geossistema, por uma corrente de geógrafos liderados por Sotchava, Bertrand e Tricart, entre outros, a qual considera o espaço como um todo articulado, como um sistema biofísico composto pelo clima, rochas, solo, água, vegetação etc, onde a presença do homem pode ser a razão para o equilíbrio ou não do ambiente.

Ampliando a discussão e sua proposta inicial, Bertrand e Bertrand (2007) reelaboram a abordagem geossistêmica, introduzindo a integração do trinômio Geossistema, Território e Paisagem (GTP). Pissinati e Archela (2009) sintetizaram os conceitos propostos por essa perspectiva, considerando o geossistema como um complexo formado de relações naturais existentes entre os elementos bióticos e abióticos; o território como a forma de uso político, social e econômico do espaço geográfico; e a paisagem como uma expressão cultural, manifesta através da apropriação, da utilização e do significado que é atribuído aos elementos do geossistema, pela comunidade local.

Nesse mesmo período foi concebida nos EUA a História Ambiental, como um novo campo na historiografia que, assim como o Geossistema na Geografia, compreende a necessidade de estudar a sociedade humana vinculada a um determinado espaço físico de forma integrada, onde um conjunto de 
relações se estabelece, ao longo do tempo, formando um todo articulado, complexo e indissociável (WORSTER, 1991).

Registra-se que essa nova abordagem historiográfica não visa contar a história da natureza ou da ecologia, mas estabelecer uma relação dialética entre a sociedade humana e os ambientes em que viveram ao longo do tempo. Pretende, ainda, identificar as transformações provocadas ao ambiente, verificando em que medida o uso dos recursos naturais influenciou a constituição de determinadas sociedades (WORSTER, 2003).

A hipótese apresentada sugere que a TGS, enquanto método, utilizado pela Geografia como base para a proposição do GTP, com ênfase no estudo das relações homem x natureza, secundariza os processos, isto é, as transformações no território que alteram a face da paisagem, e não valoriza o tempo, a história (SANTOS, 2004; FUINI, 2011).

Assim, o pressuposto teórico sugerido é que ao considerar os processos que implicam em construção das paisagens humanizadas esses se fazem necessariamente através da aproximação da Geografia com a História, por intermédio do método da história ambiental, tornando complementares os respectivos métodos, ao introduzir o conceito de paisagem como resultado da natureza territorializada pelo homem ao longo do tempo (WORSTER, 2003; FREITAS, 2007; MATHEWSON; SEEMANN, 2008; BARROS, 2010).

Com a finalidade de analisar a temática em foco, dividiu-se o artigo em dois itens, além desta introdução e das considerações finais. No primeiro apresentou-se o surgimento do Geossistema assentado nos postulados gerais da TGS. E o segundo, intitulado Geografia, geossistema e História ambiental, estabeleceu-se a importância da sintonia entre a Geografia e a História para uma melhor compreensão da relação entre o homem e a natureza, a partir da convergência das metodologias do geossistema e da história ambiental.

Para tanto, realizou-se análise da literatura para fundamentar a análise teórico/conceitual acerca da investigação do tema, tendo como suporte teórico, na primeira parte, uma breve discussão sobre a dialética e a TGS, utilizando as obras clássicas de Engels (1978) e Bertalanffy (2015) e os textos de Areco (1989), Vicente e Perez Filho (2003), Oliveira (2012) e Rodriguez e Silva (2013) e, na segunda parte, a base teórica para a compreensão do geossistema foram os trabalhos de Fuini (2011), Rodriguez e Silva (2002), Santos (2004), Bertrand; Bertrand (2007) e Pissinati; Archela (2009); no caso da história ambiental, foram fundamentais os trabalhos de Worster (1991, 2003), Drummond (1991, 2002), Pádua (2002, 2010), Carvalho (2004) e Soffiati (2008), e na discussão da relação entre a História e a Geografia destacam-se os trabalhos de Freitas (2007), Mathewson e Seemann (2008) e Barros (2010). 


\title{
TEORIA GERAL DOS SISTEMAS E O GEOSSISTEMA
}

O pressuposto aqui apresentado é que a Geografia utilizou a TGS a partir de um arcabouço teórico que visava repensar a dialética como método de investigação da realidade, isto é, da análise integrada do ambiente para compreensão das relações entre o homem e a natureza. O próprio Bertalanffy (2015, p. 30), em seu trabalho clássico, afirma que a Teoria Geral dos Sistemas:

\begin{abstract}
Tal como se dá com qualquer nova ideia na ciência [...], o conceito de sistema tem uma longa história. Embora o termo "sistema" propriamente não tivesse sido empregado, a história deste conceito inclui muitos nomes ilustres. Sob a designação de "filosofia natural", podemos fazê-lo remontar a Leibniz a Nicolau de Cusa [...], à medicina mística de Paracelso, à visão da história de Vico e Ibn-Kaldun [...], à dialética de Marx e Hegel, para não mencionar mais do que alguns poucos nomes dentre uma rica panóplia de pensadores [...].
\end{abstract}

Para Rodriguez e Silva (2002, p. 96), “a concepção sobre a paisagem como uma totalidade dialética de base natural, foi desenvolvida principalmente na União Soviética, e posteriormente em outros países do mundo socialista". Para os autores, uma das condições que permitiu o surgimento dessa nova abordagem foi “[...] o uso do Marxismo [...] que privilegiava a análise dialética das totalidades e das interações dos fenômenos $[\ldots]^{\prime \prime}$.

Sobre essa questão, ao reforçar a importância do uso da TGS para compreender a complexidade das questões ambientais, Tricart (1977, p. 19) assevera:

\begin{abstract}
O conceito de sistema é, atualmente, o melhor instrumento lógico de que dispomos para estudar os problemas do meio ambiente. Ele permite adotar uma atitude dialética entre a necessidade da análise - que resulta do próprio progresso da ciência e das técnicas de investigação - e a necessidade, contrária, de uma visão de conjunto, capaz de ensejar uma atuação eficaz sobre esse meio ambiente. Ainda mais, o conceito de sistema é, por natureza, de caráter dinâmico e por isso adequado a fornecer os conhecimentos básicos para uma atuação [...].
\end{abstract}

Assim como a TGS, a dialética parte da concepção de que todos os fenômenos naturais e sociais estão interligados, mantendo uma relação de interdependência e influência mútua com os demais fenômenos (ENGELS, 1978).

No entanto, é preciso deixar claro que a Dialética e a Teoria Geral dos Sistemas partem de bases epistêmicas distintas. De acordo com Areco (1989, p. 201), “[...] ambos os modelos se propõem à concepção do todo a partir das partes, mas o fazem de maneira diferente [...]". Para a autora, a TGS "[...] estuda a parte dentro do todo de acordo com a natureza dinâmica e harmoniosa entre elas. A dialética percebe o todo entendendo as partes pelos seus sentidos históricos e na medida de suas ligações humanas", e arremata:

\footnotetext{
O sistemismo se reporta à natureza. É essa quem vai dar-lhe a chave da interpretação do mundo. É a partir dos organismos vivos que se tem a compreensão dos organismos todos. Na dialética a interpretação do mundo, inclusive da própria natureza, é dada a partir da sociedade, ou seja, do privilégio que se dá aos fenômenos sociais, como é o caso das relações do homem no trabalho. $O$ trabalho é entendido como forma de integração do homem na natureza e visto como o "via a ser"
} 
contínuo das formações sociais. Este caráter histórico se contrapõe ao sistemismo pela sua peculiaridade em entender o mundo como provisório, instável e precário ao invés de naturalmente harmonioso (ARECO, 1989, p. 201).

Assim, guardadas as devidas diferenças entre a Teoria Geral dos Sistemas e a Dialética, entende-se, numa e noutra perspectiva, que os fenômenos somente podem ser compreendidos, em toda a sua complexidade, se vistos de forma integrada e holística. Dessa forma, pode-se afirmar que a TGS supõe o seguinte ideário:

\begin{abstract}
Trata-se do próprio delineamento de uma proposta de cunho multidisciplinar que transcende o ambiente físico-químico ou sócio-cultural stricto sensu, buscando a complexidade do ambiente percebido pelo Homem como o verdadeiro espaço para a necessária interação entre aplicação/compreensão, onde o ambiente e sua complexidade nos re-ensina a apreendê-lo como um todo, abrangendo relações físicas, químicas, biológicas, e sócio-culturais (VICENTE, L. E.; PEREZ FILHO, A., 2003, p. 331).
\end{abstract}

Segundo Vicente e Perez Filho (2003, p. 336), a expansão da teoria geossistêmica ocorreu quando "Sotchava [...], no início da década de 1960, aplica a Teoria Geral dos Sistemas de Bertalanffy, incorporando-a ao âmbito das Ciências Naturais”. Para os autores, os Geossistemas são "[...] 'formações naturais' que obedecem à dinâmica dos fluxos de matéria e energia, inerentes aos sistemas abertos que, conjuntamente com os aspectos antrópicos", formando "um modelo global de apreensão da paisagem, inserindo, pois, de maneira isonômica, o homem na sua interação com o meio natural e na formação e evolução da paisagem".

Nesse contexto, Oliveira (2012, p. 66-68) resgata os principais teóricos da concepção geossitêmica para explicar as transformações da paisagem:

A definição de paisagem proposta por Bertrand, em 1968, é admitida como suporte ao desenvolvimento das discussões ora apresentadas. O autor define paisagem como o resultado da combinação dinâmica, portanto instável, de elementos físicos, biológicos e antrópicos [...]. Em 1972, Sotchava, em seus estudos teórico-metodológicos, chama a atenção para a análise geossistêmica da paisagem, considerando a interação entre os fatores naturais e a sociedade humana. Nesse contexto, o autor apontou, já naquela época, para a necessidade de pesquisas que considerassem integralmente os fenômenos ditos naturais e os fenômenos socioeconômicos [...].

Portanto, a análise integrada e totalizante da TGS foi utilizada para dar suporte à análise das relações entre as sociedades e os ambientes onde vivem ou viveram, resultando no conceito de Geossistema (GTP), para entender os ambientes naturais e a posterior ocupação humana, com a constituição do território, cujo resultado foi a formação da paisagem. Com base nessa lógica, Vicente e Perez Filho (2003, p. 337) indicam a forma de compreender a articulação dessas três dimensões (geossistema, território e paisagem):

[...] sob a luz dos conceitos básicos de sistema, analisamos o Geossistema como a transformação do "meio natural", tendo a ação antrópica como processos que imputam mudanças sobre esse ambiente. Reconhecemos, portanto, o meio natural como estrutura principal e a ação antrópica como um dos principais agentes de "desequilibrio", sendo essa interação que determina a compreensão da dinâmica do Geossistema. 
A partir das contribuições da TGS para a proposição do método Geossistêmico, ampliado posteriormente para GTP (BERTRAND; BERTRAND, 2007), gerou como desdobramento a chamada Teoria da Complexidade, no campo da Geografia. Assim, o pressuposto da análise integrada do conjunto das relações sociais e espaciais foi decisivo para formação dos territórios e das paisagens, no processo de transformação dos ambientes naturais, desembocando em uma teoria mais ampla e, de fato, mais complexa. Dessa forma, mais uma vez, o método dialético é o passaporte para o desenvolvimento da teoria:

[...] A complexidade tem sido considerada como uma propriedade emergente dos sistemas, como um atributo sistêmico. Neste caso, a complexidade é uma abordagem que se baseia na Teoria de Sistemas, apoiada em uma concepção dialética, assumindo que nada está definido em si mesmo, mas que parte de contextos espaço-temporais, que formam processos conexos e integrados [...]. A dialética é, assim, o exercício totalizador que pode apreender a síntese de múltiplas determinações que compõe a unidade. A dialética é uma metodologia que permite o diálogo crítico com outras abordagens científicas [...]. Isso se aplica principalmente à Teoria da Complexidade [...] (RODRIGUEZ.; SILVA., 2013, p. 30).

Rodriguez e Silva (2013, p. 29) ressaltam que a ideia de complexidade leva necessariamente a uma visão de totalidade, na análise dos fenômenos físicos e sociais, ao considerar as relações como um todo "[...] e viceversa. Dessa forma, os princípios desenvolvidos pela Teoria da Complexidade estão muito perto da visão sistêmica da complexidade que havia sido proposta por Engels em sua Dialética da Natureza [...]". Nessa obra clássica, publicada no final do século XIX, Engels (1978, p. 58-59), usando o método dialético, lembra que de nada adianta conhecer plenamente a árvore se o observador perde de vista a dimensão da floresta, ou seja:

Toda a natureza que nos é acessível constitui um sistema, um conjunto coerente de corpos; por corpos entendemos todas as realidades materiais [...]. O facto de estes corpos estarem em relação recíproca já implica que agem uns sobre os outros, e esta ação recíproca é precisamente o movimento. Já aqui nos é possível constatar que a matéria é impensável sem o movimento. E visto que a matéria [...], tão impossível de criar como de destruir, isso implica que o movimento é igualmente tão impossível de criar como de destruir. Esta conclusão é inelutável a partir do momento em que se tenha reconhecido o universo como um sistema, como um conjunto coerente de corpos [...].

Fundamentado nessa contextualização, inqueriu-se que a Geografia, ao incorporar o GTP, passou também a levar em conta, na análise do espaço físico, as transformações que as atividades humanas produziram nesses ambientes (SANTOS, 2004). Isto é, por incorporar a noção de processo histórico, a Geografia se aproximou da História ao construir os conceitos de território e paisagem (BERTRAND, BERTRAND, 2007). Da mesma forma, como veremos na sequência, a História, para além da noção de tempo, incluiu a concepção de espaço, na análise do processo histórico, e estreitou ainda mais suas relações com a Geografia.

\section{GEOGRAFIA, GEOSSISTEMA E HISTÓRIA AMBIENTAL}

Salienta-se que a utilização da teoria e metodologia do Geossistema (GTP) contribui para a compreensão de que o território consiste no conjunto das interações dos homens com a natureza em determinado espaço, 
enquanto que a paisagem se constitui na expressão do universo visível resultante das transformações antrópicas produzidas no ambiente. Nesse sentido, Rodriguez e Silva (2002, p. 98), entendem que:

A paisagem cultural como nível superior do estudo da paisagem, como sistema ambiental, representa a dimensão sócio-ecológica da paisagem. São os espaços geográficos que as sociedades transformam para produzir, habitar e sonhar. Concebida assim, a paisagem é a interface da Natureza com a Sociedade. Aceita-se de tal modo e por uma parte, a materialidade, ou seja, a existência de uma estrutura e um conjunto próprio dos corpos naturais (a paisagem natural), e a existência de um status paisagístico desses corpos naturais, determinado pelo sistema de produção econômica e cultural [...]. A paisagem é, assim, uma noção diagonal, transdisciplinar, que permite a articulação sócio-espacial.

Para Fuini (2011, p. 48), no entanto, “[...] o conhecimento real de um espaço não é dado somente por relações, mas também por processos [...]". Dessa maneira, acentua que a Geografia precisa considerar não apenas o espaço e o conjunto de relações sociais que se estabeleceram em determinado local, mas também o processo histórico que levou à transformação dos ambientes naturais, dando origem aos territórios e às paisagens. Portanto, reconhece a relevância de que o espaço geográfico é:

\begin{abstract}
[...] o espaço formado por um conjunto indissociável, solidário e também contraditório, de sistemas de objetos e sistemas de ações, não considerados isoladamente, mas como quadro único no qual a história se dá [...]. Deste modo, a função é a atividade elementar de que a forma se reveste, sendo as formas resultantes de processos passados ocorridos na estrutura subjacente. Ao se refletir sobre os diferentes tipos de estruturas, aí estão as diferentes formas reveladas (naturais e artificiais) que ficam, por sua vez, sujeitas à constante evolução [...]. Parece ter sido este o elemento ausente na tradição sistêmica em Geografia. A ausência das considerações sobre o tempo histórico e sua influência sobre as variáveis de um sistema sócio-espacial [...] (FUINI, 2011, p. 49). (grifo nosso).
\end{abstract}

Nesse contexto, Fuini (2011), embora julgue o GTP um avanço teórico e metodológico, claramente apresenta uma crítica aos seus autores por terem considerado as relações entre a sociedade e a natureza como alicerces na constituição do território e da paisagem, porém não incluíram a variável histórica como fundamental e indispensável. Para reforçar sua tese, o autor vai buscar inspiração em Milton Santos, que reforça a ideia da necessidade da articulação teórica da relação entre a sociedade e a natureza, mediada pelo tempo histórico, isto é:

\footnotetext{
O exercício da apreensão da totalidade é um trabalho fundamental e básico para a compreensão do lugar real e epistemológico que, dentro dela, têm as suas diferentes partes e aspectos. Todavia, o conhecimento das partes, isto é, do seu funcionamento, de sua estrutura interna [...], da sua própria evolução, constituem um instrumento fundamental para o conhecimento da totalidade. Uma interdisciplinaridade que não leva em conta a multiplicidade de aspectos com os quais se apresenta aos nossos olhos uma mesma realidade, poderia conduzir à construção teórica de uma totalidade cega e confusa, incapaz de permitir uma definição correta de suas partes, agravando o problema de sua própria definição como realidade total. Isto supõe que se reconheça um objeto à Geografia e que se hajam identificado suas categorias fundamentais. É bem verdade que as categorias mudam de significação com a história, mas elas são uma base e guia permanente para teorização [...]. Em realidade, $[\ldots]$ é $[. .$.$] preciso partir do próprio objeto de nossa disciplina, o espaço, tal como ele se$ apresenta, como um produto histórico [...] (SANTOS, 2004, p. 141). (grifo nosso).
}

Nesse sentido, sugere-se que o elo de ligação da História com a Geografia pode ser encontrado na história ambiental (WORSTER, 1991; FREITAS, 2007; MATHEWSON; SEEMANN, 2008; BARROS, 2010). 
Na opinião de Freitas (2007, p. 23), “[...] a História Ambiental apresenta muitos pontos de interesse comum [...]" com a Geografia "[...] e vice-versa e que, sendo assim, os geógrafos não podem deixar de estar atentos às propostas que os historiadores ambientais trazem para o campo das ideias sobre as relações entre natureza e sociedade". Para a autora (2007, p. 31), “[...] ambas encaram o homem como transformador do meio ambiente, mas sabem que essas transformações sofrem restrições do ambiente físico [...]".

A história ambiental surgiu de uma nova geração de historiadores preocupados com a emergência da crise ambiental, no final dos anos de 1960 e início dos anos de 1970 e, a partir de então, a história e o meio ambiente começaram a conformar um novo ramo de pesquisa. Pioneiramente nos EUA, mas posteriormente expandiu-se para a Europa e no final da década de 1980 chegou ao Brasil (CARVALHO, 2004).

Segundo Worster (1991, p. 201), historiador norte-americano e um dos fundadores dessa nova abordagem historiográfica, "a história ambiental trata do papel e do lugar da natureza na vida humana". Para Duarte (2005), esse cenário configura-se de grande importância, em virtude do surgimento dessa nova especialidade na história.

Em conformidade com Worster, essa nova abordagem não visa contar a história da natureza ou da ecologia, mas estabelecer uma relação dialética entre a sociedade humana e os ambientes em que viveram ao longo do tempo, identificar as transformações provocadas ao meio e verificar em que medida o uso dos recursos naturais influenciou a constituição de determinadas sociedades. De acordo com o autor (2003, p. 25), portanto, embora a natureza tenha a sua própria historicidade, o objetivo da história ambiental é compreender a relação do homem com a natureza, pois:

\begin{abstract}
Assim, definida etimologicamente, a história ambiental lida com o papel e o lugar da natureza na vida humana. Ela estuda todas as interações que as sociedades do passado tiveram com o mundo não humano, o mundo que não criamos em nenhum sentido primário. $O$ ambiente tecnológico, o conjunto de coisas que as pessoas produziram, que pode ser tão onipresente a ponto de constituir um tipo de "segunda natureza" em torno dela, também é parte deste estudo, mas no sentido muito específico em que a tecnologia é um produto da cultura humana assim como condicionada pelo ambiente nãohumano. Mas, diante de tais fenômenos, como o deserto e o ciclo da água, nós encontramos energias autônomas e independentes que não derivam das tendências e invenções de nenhuma cultura [...].
\end{abstract}

Para Soffiati (2008, p. 16), que utiliza a expressão eco-história, "trata-se dos estudos concernentes às relações das sociedades humanas com um determinado ecossistema, ou com um conjunto inter-relacionado deles (bioma), ou, ainda, com uma região apresentando relativa unidade ambiental [...]", bem com, “considerando também a natureza não-humana como um agente histórico que 'fala' de alguma forma ante as relações que se estabelecem entre ela e as antropossociedades".

Conforme Drummond (1991, p. 194), a historiografia "tem sido incapaz de esclarecer exatamente os tipos de sociedade gerados pela exploração de um recurso natural ou de vários recursos simultaneamente, ou de vários recursos em sequência". Realça que tal constatação derivou da compreensão de que a história 
ambiental objetiva "identificar, em escala regional e local, que tipos de sociedade se formaram em torno de diferentes recursos naturais, que permanência teve essas sociedades e que tipo de consequências elas criaram para os seus ambientes sustentarem outros tipos de sociedade".

Assentado nessa concepção, identificou-se uma clara convergência entre a história ambiental e a geografia. De acordo com Barros (2010, p. 73), “[...] quando os historiadores deram-se conta da necessidade de [...] colocar em um mesmo nível as noções de tempo e espaço, logo começaram a dialogar com conceitos mais tradicionais da Geografia [...]" como território e paisagem. Para o autor (2010, p. 76), “[...] homem, espaço e tempo aparecem como três fatores indissociáveis. Se o Espaço está sujeito aos ditames do Tempo, por outro lado a Temporalidade também está sujeita aos ditames do Espaço e do meio geográfico [...]”.

Rodriguez e Silva (2002, p. 98), sustentados em uma visão geossistêmica (GTP), deixam claro que a metodologia precisa levar em conta "[...] duas categorias de sistematização: a tipologia e a regionalização. A tipologia significa distinguir as unidades pela sua semelhança e repetição, dependendo de determinados parâmetros de homogeneidade", enquanto que "a regionalização significa determinar as unidades pela sua personalidade e individualidade $[\ldots]^{\prime \prime}$.

Nesse contexto, adenda-se ainda que, do ponto de vista do método, Drummond (1991) afirma que o historiador ambiental busca estabelecer, como premissa, a delimitação do campo de pesquisa, ao definir recortes assentados em uma determinada região ou bacia hidrográfica e um dado bioma, cidade, ou área agrícola, paisagem desmatada ou degradada, etc.

Assim, resgata-se, mais uma vez, a visão geossistêmica sobre a articulação integrada entre o ambiente natural, o território e a paisagem (GTP) e as ações antrópicas, ou seja, uma dimensão espaço-temporal. Logo, de acordo com Rodrigues e Silva (2002, p. 98), “[...] é necessário diferenciar e classificar as paisagens naturais, ou seja, os corpos naturais. Depois, é preciso distinguir as formas de ocupação (densidade, intensidade e tipos de ocupação)", e, por fim, mas não menos importante, é necessário "passar à classificação das paisagens culturais. Esse procedimento permitirá entender como se dá a transformação das paisagens naturais em paisagens culturais [...]".

Nessa mesma perspectiva, Worster (1991, p. 202) apresenta uma metodologia muito semelhante ao GTP, ao ressaltar que:

[...] Há três níveis em que a nova história funciona, três conjuntos de questões que ela enfrenta [...], três grupos de perguntas que ela procura responder, cada um deles exigindo contribuições de outras disciplinas e aplicando métodos especiais de análise. O primeiro trata do entendimento da natureza propriamente dita, tal como se organizou e funcionou no passado. [...] O segundo nível da história ambiental introduz o domínio socioeconômico na medida em que este interage com o ambiente. [...] Por fim, formando um terceiro nível de análise para o historiador, vem aquele tipo de interação mais intangível e exclusivamente humano, puramente mental ou intelectual, no qual percepções, valores 
éticos, leis, mitos e outras estruturas de significação se tornam parte do diálogo de um indivíduo ou de um grupo com a natureza [...].

Com base nessa configuração, a teoria e a metodologia da história ambiental, concebida por Worster (1991, 2003), pressupõe, inicialmente, caracterizar a área objeto de estudo, relativamente à vegetação, solo, relevo, cursos d'agua, ou seja, identificar os recursos naturais e o tipo de sociedade presente no ambiente. No segundo momento, estudar as relações econômicas e sociais para compreender o processo de uso dos recursos naturais pelos indivíduos ao longo do tempo, em determinado espaço geográfico, com vistas a verificar as mudanças derivadas da ação humana. E o terceiro passo relaciona-se ao plano das ideias e da cultura, com o intuito de interpretar em que medida a sociedade, ao sofrer os impactos decorrentes das transformações do espaço, adota medidas, tecnologias, leis, mitos que visam harmonizar e ou confrontar o universo estabelecido entre os homens e a natureza. De acordo com o autor, "[...] o grande desafio da nova história não está em meramente identificar tais níveis de indagação, mas em decidir como e onde fazer as conexões entre eles [...]" (WORSTER, 2003, p. 27).

Na opinião de Freitas (2007, p. 29-30), “[...] poderíamos reforçar a tese de que, a princípio, os três níveis de questões apontadas pela História Ambiental têm relação direta com os objetos da Geografia em geral e seus temas mais recorrentes", pois "[...] o entendimento da natureza propriamente dita; o domínio socioeconômico, que dá origem às técnicas, às ferramentas de trabalho, aos modos de produção, às relações sociais, às instituições e às decisões ambientais; e a percepção, ideologia, memória, valores e ideias [...]" que a sociedade produz na sua relação com a natureza, tem relação direta com os conceitos de território e paisagem (GTP), utilizado sem suas pesquisas pelos geógrafos.

Segundo Mathewson e Seemann (2008, p. 74), um dos precursores dessa aproximação entre a Geografia e a História, que permitiu o nascimento nos anos de 1970 da história ambiental, foi o geógrafo norteamericano Carl Sauer que, sob influência do conceito de paisagem cultural, dos autores alemães, e da abordagem histórico-regional, dos franceses, a partir dos anos de 1920, desenvolveu pesquisas e publicou trabalhos na perspectiva de uma história cultural do meio ambiente, "[...] uma abordagem que mostra muitos paralelos e afinidades com diversas correntes da história ambiental contemporânea". De acordo com esses autores (2008, p. 76):

\footnotetext{
Ao enfatizar a ação humana na transformação da paisagem, Sauer atacou o determinismo ambiental que dominava a geografia norte-americana naquela época. Sob uma perspectiva histórica, pode-se diferenciar entre paisagens naturais (definidas como áreas anteriores às atividades humanas) e paisagens culturais que correspondem aos processos de modificação da paisagem natural por meio da ação e das obras humanas. Em outras palavras, são as atividades humanas transformadoras e não as influências dos elementos naturais que ocupam uma posição central nos estudos da paisagem: "a cultura é o agente, a área natural é o meio, a paisagem cultural é o resultado". Ao aplicar seu conceito de paisagem ao meio ambiente, Sauer criou uma "ecologia geográfica" ou ecologia da paisagem que se distinguia da ecologia dos biólogos e da ecologia humana dos sociólogos. Para Sauer, a paisagem do presente era a "consequência histórica da interação entre o organismo e o ambiente". Levantamentos de dados em acervos e bibliotecas e extensas pesquisas de campo com eventuais escavações faziam
} 
parte dessa viagem do presente ao passado na qual se procurava saber como a paisagem chegou a ter a sua forma atual.

Para Carvalho (2004), uma das principais contribuições da história ambiental encontra-se no resgate da memória, através de pesquisas a respeito das relações dos homens com os ambientes em que viveram e o uso que fizeram e fazem dos recursos naturais disponíveis, e como esse conhecimento pode despertar a sociedade atual. Esta possibilita a sensibilização sobre a necessidade do uso racional e sustentável dos ativos ambientais, com o propósito de evitar que os erros do passado possam se repetir no presente e no futuro.

Dessa forma, destaca-se que o historiador norte-americano Dean (1996, p. 379) ao pesquisar a devastação da Mata Atlântica no Brasil, averigua que o conhecimento desse passado pode ajudar a preservar outros biomas, como a Floresta Amazônica, por meio do questionamento: “[...] não deveria esse holocausto produzido pelo homem ser relatado de geração para geração?" E acrescenta: "não deveria o manual de história aprovado pelo Ministério da Educação começar assim: 'crianças, vocês vivem em um deserto; vamos Ihes contar como foi que vocês foram deserdadas' [...]".

Nessa mesma linha de entendimento, Soffiati (2008, p. 24) indaga: “[...] em termos pragmáticos, para que serve a eco-história?". E, em contraposição a um grupo de historiadores que "[...] dizem que a história não serve para nada, quando muito para explicar processos", o autor arremata que "[...] a eco-história, diante da crise atual deste campo de saber, afirma que o campo descortinado por ela explica e ajuda a mudar a realidade".

Todavia, Pádua (2010, p. 96-97) chama a atenção para o fato de que não se deve julgar as gerações passadas utilizando conceitos e valores atuais, uma vez que:

[...] É essencial, no entanto, evitar o anacronismo e a pretensão de que os indivíduos do passado possam ser cobrados em razão de categorias tão modernas quanto são ecologia, sustentabilidade, impactos da ação humana etc. É preciso entender cada época no seu contexto geográfico, social, tecnológico e cultural. [...] A pesquisa em história ambiental [...] se dá por meio de recortes geográficos e biofísicos concretos: uma região florestal, uma bacia hidrográfica, uma cidade, uma zona agrícola etc. [...] A história ambiental, como ciência social, deve sempre incluir as sociedades humanas. Mas também reconhecer a historicidade dos sistemas naturais. O desafio [...] é construir uma leitura aberta e interativa da relação entre ambos.

Com base nesse entendimento, concorda-se com a assertiva de Worster (1991, p. 205) de que os homens provocam transformações e não degradação ao ambiente propriamente dito, pois "a dificuldade de definir os danos sofridos por um ecossistema se aplica a mudanças causadas tanto pelos homens quanto por forças não-humanas [...]". Assim, "[...] o historiador ecológico acaba preferindo dizer que os homens provocam 'mudanças' no ambiente - pois 'mudanças' é um termo neutro e incontroverso - e não 'danos', um conceito muito mais problemático". 
Nessa perspectiva, segundo Pádua (2002), as origens das preocupações ambientais no Brasil são anteriores ao processo de industrialização, pois remontam ao período da independência do Brasil, numa época em que não havia legislação ambiental e a consciência ecológica ainda era muito baixa no seio da sociedade. Tal constatação decorre da análise de diversos discursos, de uma parcela minoritária da elite brasileira, que alertavam para o uso dos recursos naturais de forma irracional e desordenado, inclusive com previsões pioneiras ao risco da desertificação, explicitadas por intelectuais como José Bonifácio de Andrada e Silva e Joaquim Nabuco, entre outros.

Fundamentada nesse contexto, Duarte (2005, p. 32) enfatiza a importância de que “[...] compreender a historicidade das relações entre a sociedade e a natureza pode, certamente, dar-nos instrumentos para assumir uma postura mais crítica frente aos debates sobre o ambiente". Patenteia que a relevância do conhecimento histórico evidencia que "tornarmo-nos mais capazes de perceber [...] tanto as falácias do desenvolvimento como as idealizações autoritárias de algumas propostas ecológicas ditas 'alternativas' [...]”.

Sendo assim, acrescenta-se, em conformidade com Drummond (2002, p. 30),

[...] que a comunidade de cientistas sociais e afins precisa estudar melhor e incorporar analiticamente as variáveis biofísicas, superando um receio infundado de sucumbir a "determinismos" naturalistas, trilhando os caminhos abertos por alguns clássicos de nossas disciplinas, como Caio Prado Jr., Gilberto Freyre, Darcy Ribeiro e Sérgio Buarque de Holanda. Esses caminhos ficaram abandonados por muito tempo e precisam ser desbravados "a facão", para dar acesso à "fronteira" ainda inexplorada dos estudos sócio-ambientais [...].

Por conseguinte, entende-se que a história ambiental encerra caráter interdisciplinar, por recorrer ao diálogo sistemático com as demais ciências humanas e naturais, para ilustrar e fortalecer a compreensão do complexo universo das relações entre a sociedade e o ambiente. Assim, destaca-se que vem da geografia um dos principais suportes para a pesquisa nessa área de estudo. Destarte, em consonância com Worster (1991, p. 213-214), a relação entre a História e a Geografia se apresenta de forma muito clara:

[...] Os historiadores ambientais vêm se apoiando em muitos geógrafos para chegar às suas conclusões. [...] Os geógrafos, tal como os historiadores, tenderam a ser mais descritivos do que analíticos. Elegendo os lugares, ao invés das épocas, como o seu ponto focal, eles mapearam a distribuição das coisas, tal como os historiadores narraram sequências de eventos. Os geógrafos se deliciaram com uma boa paisagem, tanto quanto os historiadores com uma boa estória. Ambos exibiram um apego pelo particular e resistiram às generalizações fáceis, qualidade que talvez seja a sua virtude e força comuns. Mas eles também se parecem nas suas fraquezas, acima de tudo na sua tendência recorrente a perder de vista a relação fundamental homem-natureza: os historiadores, quando mediram o tempo apenas em termos de eleições e dinastias, os geógrafos quando tentaram reduzir a terra e as suas complexidades à ideia abstrata de "espaço". Natureza, terra, clima, ecossistemas - essas são as entidades relevantes. Quando e onde os geógrafos se ocuparam dessas forças, eles ofereceram muito para a nova história, em termos de informação. Mais importante, foram principalmente os geógrafos que nos ajudaram a perceber que a nossa situação não é mais a de sermos moldados pelo ambiente. Ao contrário, hoje em dia nós é que cada vez mais estamos assumindo a moldagem, e com consequências muitas vezes desastrosas. Hoje a responsabilidade comum das duas disciplinas é descobrir por que os povos modernos têm desejado tanto escapar das restrições da natureza e quais têm sido os efeitos ecológicos desse desejo. 
Portanto, assentado na análise realizada até aqui, ressalta-se a relevância de, por um lado, fazer a adequada articulação da esfera econômica e a cultural com o ambiente, o espaço físico, onde as sociedades se desenvolveram historicamente e, por outro lado, de articular, juntar, numa mesma análise o que nunca foi separado: o mundo das relações entre a humanidade e o meio ambiente, rompendo definitivamente com o falso dualismo entre o homem e a natureza.

\section{CONSIDERAÇÕES FINAIS}

Através da análise e interpretação da literatura em foco, demonstrou-se a contribuição da Teoria Geral dos Sistemas (TGS) para a Geografia desenvolver a metodologia do Geossistema (GTP). Todavia, sem embargo desse reconhecimento, realce-se que a crítica à TGS pode ser estendida também à GTP, a despeito de considerá-las como avanço teórico e metodológico, sobretudo pelo uso da dialética, da visão holística e integrada do ambiente, e do desenvolvimento dos conceitos de território e paisagem, pois os mesmos focam prioritariamente as relações, sendo assim, secundarizam os processos, o tempo, na análise do universo envolvendo a humanidade e a natureza.

Logo, em função dessa constatação e com o intuito de superar essa problemática, comprovou-se a possibilidade de aperfeiçoar a metodologia do GTP através da utilização da teoria e do método da história ambiental, na perspectiva de aproximar ainda mais a Geografia da História, particularmente nas pesquisas que abrangem estudos acerca da relação entre as sociedades e os ambientes onde viveram ao longo do tempo.

\section{REFERÊNCIAS}

ARECO, M. B. A. Sistemismo x Dialética: uma questão de diferenciação de propostas. Transinformação, Campinas, v. 1, n. 2, p. 195203, maio/ago, 1989.

BARROS, J. D. A. Geografia e História: uma interdisciplinaridade mediada pelo espaço. Geografia, Londrina, v. 19, n. 3, p. 67-84, 2010. BERTALANFFY, L. V. Teoria geral dos sistemas: fundamentos, desenvolvimento e aplicações. Tradução de Francisco M. Guimarães. 8a ed. Petrópolis, RJ: Vozes, 2015.

BERTRAND, G. Paisagem e Geografia Física Global: esboço metodológico. Cadernos de Ciências da Terra. São Paulo: Instituto de Geografia da Universidade de São Paulo, n. 13, 1972. Tradução de Olga Cruz. Paysage et geographie physique globale. Esquisse méthodologique. Revue Geógraphiquedes Pyrénéeset du Sud-Ouest, Toulouse, v. 39, n. 3, p. 249-272, 1968.

BERTRAND, G; BERTRAND, C. Uma geografia transversal e de travessias: o meio ambiente através dos territórios e das temporalidades. Org. Messias Modesto Passos. Maringá: Massoni, 2007.

CARVALHO, E. B. A história ambiental e a "crise ambiental" contemporânea: um desafio político para o historiador. Esboços, Florianópolis, v. 11, n. 11, p. 105-117, 2004.

DEAN, W. A ferro e fogo: a história e a devastação da Mata Atlântica brasileira. São Paulo: Companhia das Letras, 1996.

DRUMMOND, J. A. A história ambiental: temas, fontes e linhas de pesquisa. Estudos Históricos, Rio de Janeiro, v. 4, n. 8, p. 177-197, 1991. 
DRUMMOND, J. A. A. Por que estudar a história ambiental do Brasil? Ensaio temático. Varia História, Belo Horizonte, v. 26, n. 1, p. 13-32, jan. 2002.

DUARTE, R. H. História \& natureza. Belo Horizonte: Autêntica, 2005.

ENGELS, F. Dialética da Natureza. Tradução de Joaquim J. de M. Ramos e Eduardo L. Nogueira. 2 ed. Rio de Janeiro: Martins Fontes, 1978.

FREITAS, I. A de. História Ambiental e Geografia: Natureza e cultura em interconexão. Geo UERJ. Rio de Janeiro, Ano 9, v. 2, n. 17, 2은 semestre de 2007.

FUINI, L. L. A Abordagem Sistêmica e a questão da dicotomia Físico/Social na Ciência Geografia. Revista Ciência Geográfica. Bauru: v. 15, n. 1. Jan./Dez. 2011, p.45-51.

MATHEWSON, K.; SEEMANN, J. A geografia histórico-cultural da Escola de Berkeley: um precursor ao surgimento da História Ambiental. Varia História, Belo Horizonte, v. 24, n. 39, p. 71-85, UFMG, 2008. Disponível em: http://www.redalyc.org/pdf/3844/384434824004.pdf. Acesso em: jun. 2018.

OLIVEIRA, R. C. de. Zoneamento ambiental como instrumento do planejamento físico territorial. In: SILVA. C. A. da. (Org.). Geografia e Natureza: experiências e abordagens de pesquisa. Ed. UFGD, 2012.

PÁDUA, J. A. Um sopro de destruição: pensamento político e crítica ambiental no Brasil escravista (1786-1888). Rio de Janeiro: Jorge Zahar, 2002.

PÁDUA, J. A. As bases teóricas da história ambiental. Estudos Avançados, São Paulo, v. 24, n. 68, p. 81-101, São Paulo, 2010.

PISSINATI, M. C.; ARCHELA, R. S. Geossistema, Território e Paisagem - método de estudo da paisagem rural sob a ótica bertrandiana. Geografia, Londrina, v. 18, n. 1, jan/jun. 2009, p. 5-31. Disponível em http: <//www.uel.br/revistas/uel/index.php/geografia/>. Acesso em: 12 nov. 2011.

RODRIGUEZ, J. M.M.; SILVA, E. V. da. A Classificação das paisagens a partir de uma visão Geosistêmica. Mercator - Revista de Geografia da UFC, ano 01, número 01, 2002.

RODRIGUEZ, J. M.M.; SILVA, E. V. da. Planejamento e gestão ambiental: subsídios da geoecologia das paisagens e da teoria geossistêmica. Fortaleza: Edições UFC, 2013.

SANTOS, M. Por uma Geografia nova: Da Crítica da Geografia a uma Geografia Crítica. 6 ed. São Paulo: Editora da USP, 2004 (Coleção Milton Santos; 2).

SOFFIATI, A. Algumas palavras sobre uma teoria da eco-história. Desenvolvimento e Meio Ambiente, n. 18, p. 13-26, Curitiba, Editora UFPR, 2008.

TRICART, J. Ecodinâmica. Rio de Janeiro: IBGE, 1977.

VICENTE, L. E.; PEREZ FILHO, A. Abordagem sistêmica e geografia. Geografia-Ageteo. Rio Claro, v. 28, n. 3, set./dez. 2003 , p. 323-344.

WORSTER, D. Para fazer história ambiental. Tradução de José Augusto Drummond. Estudos Históricos, Rio de Janeiro, v. 4, n. 8, p. 198-215, 1991.

WORSTER, D. Transformações da Terra: para uma perspectiva agroecológica na História. Tradução de Maria Clara Abalo Ferraz de Andrade. Ambiente e Sociedade. Campinas, v. 5, n. 2, p. 23-44, 2003. 